\title{
Correction to: Liquid biopsy and tumor heterogeneity in metastatic solid tumors: the potentiality of blood samples
}

Marco Russano ${ }^{1}$, Andrea Napolitano ${ }^{1}$, Giulia Ribelli ${ }^{1 *}$, Michele Iuliani ${ }^{1}$, Sonia Simonetti ${ }^{1}$, Fabrizio Citarella', Francesco Pantano', Emanuela Dell'Aquila', Cecilia Anesi ${ }^{1}$, Nicola Silvestris ${ }^{2,3}$, Antonella Argentiero ${ }^{2}$, Antonio Giovanni Solimando ${ }^{2,4}$, Bruno Vincenzi ${ }^{1}$, Giuseppe Tonini ${ }^{1}$ and Daniele Santini ${ }^{1}$

\section{Correction to: J Exp Clin Cancer Res 39, 95 (2020) https://doi.org/10.1186/s13046-020-01601-2}

Following publication of the original article [1], the authors identified an error in the author name of Antonio Giovanni Solimando.

The incomplete author name is: Antonio Solimando

The complete author name is: Antonio Giovanni Solimando

The author group has been updated above and the original article [1] has been corrected.

\begin{abstract}
Author details
${ }^{1}$ Department of Medical Oncology, Campus Bio-Medico University of Rome, Álvaro del Portillo, 21, 00128 Rome, Italy. ${ }^{2}$ Medical Oncology Unit, IRCCS-Istituto Tumori "Giovanni Paolo II" of Bari, 70124 Bari, Italy. ${ }^{3}$ Department of Biomedical Sciences and Human Oncology, University of Bari 'Aldo Moro', 70124 Bari, Italy. ${ }^{4}$ Department of Biomedical Sciences and Human Oncology, Section of Internal Medicine 'G. Baccelli', University of Bari Medical School, 70124 Bari, Italy.
\end{abstract}

Published online: 24 June 2020

\section{Reference}

1. Russano, et al. Liquid biopsy and tumor heterogeneity in metastatic solid tumors: the potentiality of blood samples. J Exp Clin Cancer Res. 2020;39:95.

The original article can be found online at https://doi.org/10.1186/s13046020-01601-2

* Correspondence: g.ribelli@unicampus.it

${ }^{1}$ Department of Medical Oncology, Campus Bio-Medico University of Rome, Álvaro del Portillo, 21, 00128 Rome, Italy

Full list of author information is available at the end of the article

(c) The Author(s). 2020 Open Access This article is licensed under a Creative Commons Attribution 4.0 International License, which permits use, sharing, adaptation, distribution and reproduction in any medium or format, as long as you give appropriate credit to the original author(s) and the source, provide a link to the Creative Commons licence, and indicate if changes were made. The images or other third party material in this article are included in the article's Creative Commons licence, unless indicated otherwise in a credit line to the material. If material is not included in the article's Creative Commons licence and your intended use is not permitted by statutory regulation or exceeds the permitted use, you will need to obtain permission directly from the copyright holder. To view a copy of this licence, visit http://creativecommons.org/licenses/by/4.0/ The Creative Commons Public Domain Dedication waiver (http://creativecommons.org/publicdomain/zero/1.0/) applies to the data made available in this article, unless otherwise stated in a credit line to the data. 